\title{
Research on high voltage control caused by small hydropower
}

\author{
Junjie Xiong ${ }^{1, a}$, Hao $\mathrm{He}^{1, \mathrm{~b}}$ and Shanlian Guan ${ }^{2, \mathrm{c}}$ \\ ${ }^{1}$ State Grid Jiangxi Electric Power Research Institute, Nanchang 330000, China \\ ${ }^{2}$ State Grid Henan Electric Power Research Institute, Zhengzhou 450000, China \\ awinter209@163.com, bhehao-0412@163.com, 'shinemun@163.com
}

Keywords: Small hydropower, High voltage.

\begin{abstract}
This paper mainly analyses on the influence of Congyi grid voltage caused by small hydropower station. The mechanism of high voltage has been expounded. Based on the ETAP simulation, comprehensive comparison of various measures of operational and governance effect has been carried out, the optimization measure has been proposed.
\end{abstract}

\section{Introduction}

Small hydropower stations have been mainly distributed in the mountainous areas where in the terminal power distribution, generally access to $10 \mathrm{kV}$ public lines or $35 \mathrm{kV}$ substations, small hydropower units mostly adopts synchronous generators, the capacity of less than 500kVA, different from thermal power grid of hydraulic turbines, it can not achieve constant voltage output, using coaxial DC exciter excitation system, through the manual adjust the excitation, only suitable for constant power factor control, the power factor is more than 0.98 .

During the wet season, a large number of small hydropower stations generating high voltage in the nearby residents, such as in recent years, electrical equipments burnout cases in Chongyi have happened caused by high voltage, therefore, must as soon as possible to solve the high voltage problem caused by small hydropower.

\section{Analysis of the effect of small hydropower on voltage}

Chongyi is located in Ganzhou where water resources are abundant, have 83 small hydropower stations, installed 159 units, the total capacity of 66.145MW shown in Table 1. At present, Congyi grid connects with Ganzhou grid through 110kV Shangchong line, Shangyang line, Chongxi line. There are 3 110kV substations: Chongyi substation, Yangmeishi substation and Guting substation; $1235 \mathrm{kV}$ stations which have 19 main transformers, the total capacity of 100.1MVA. Geographic wiring diagram of Congyi distribution is shown in Fig.1.

Table 1 Small hydropower capacity

\begin{tabular}{ccc}
\hline Numble & Station & Capacity $(\mathrm{kW})$ \\
\hline 1 & 35kV Guobu & 15170 \\
2 & 35kV Yingzigao & 14565 \\
3 & 35kV Lintan & 13720 \\
4 & 35kV Qianchang & 4225 \\
5 & 35kV Fengzhou & 4120 \\
6 & 35kV Changlong & 3710 \\
7 & 35kV Guantian & 2740 \\
8 & 35kV Zhuling & 2385 \\
9 & 35kV Mixi & 1525 \\
10 & 35kV Taxia & 1090 \\
11 & 35kV Liedu & 325 \\
12 & 110kV Guting & 13410 \\
13 & 110kV Yangmeishi & 1350 \\
\hline
\end{tabular}


The rate of over High-Limit voltage of $35 \mathrm{kV}$ substation in Chongyi during June,July and August have been shown in Table 2. Lintan and Yingzigao $10 \mathrm{kV}$ bus over High-Limit voltage is serious, should be the first to be treated.

Table 2 Over High-Limit Voltage

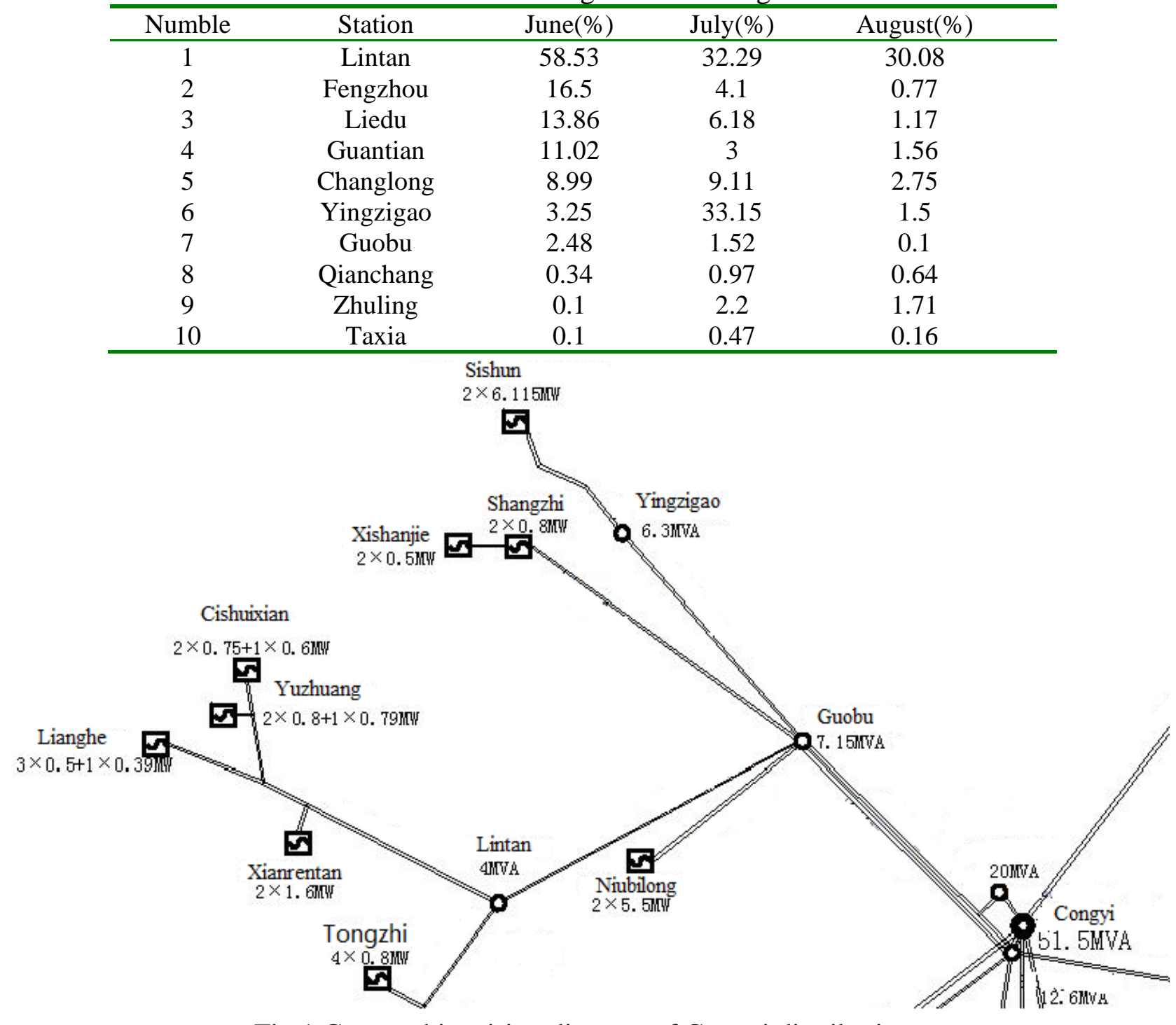

Fig.1 Geographic wiring diagram of Congyi distribution

Formula (1) shows the voltage drop of power flow transmission, in which P,Q are respectively active power and reactive power, $\mathrm{R}, \mathrm{X}$ are respectively wire resistance and reactance.

$$
\Delta U=\frac{P R+Q X}{U}
$$

In the wet season, a number of small hydropowers generate, power flow is changed from the terminal of the power distribution to substation. $U_{35}$ is higher than $U_{0}$, as shown in formula (2).

$$
U_{35}=U_{0}+\Delta U=U_{0}+\frac{P R+Q X}{U}
$$

$35 \mathrm{kV}$ wire is different in $\mathrm{R}$ and $\mathrm{X}$ from $110 \mathrm{kV}$ wire, reactance $\mathrm{X}$ general is $0.35-0.45$, while the LGJ-50 wire R is about 0.6 , LGJ-70 is 0.4 , LGJ-95 is about 0.3 ; in the wet season power factor on the $35 \mathrm{kV}$ line is very high, more than 0.98 . According to the formula (2), as an example, the voltage change in the $10 \mathrm{~km}$ LGJ-95 wire transmissed $1 \mathrm{MVA}$, active power affects $0.0811 \mathrm{kV}$, reactive power affects $0.0216 \mathrm{kV}$, active power plays a major role in the voltage change of power distribution caused by small hydropower stations. 


\section{Control measures}

$35 \mathrm{kV}$ substations supplied by $110 \mathrm{kV}$ Guting transformer are generally over High-Limit voltage, according to the wire parameter calculation of wire voltage change has been shown in Table 3 .

Table 3 Calculation results of wire voltage change

\begin{tabular}{ccccc}
\hline Numble & $\begin{array}{c}\text { Transmission } \\
\text { Line }\end{array}$ & $\begin{array}{c}\text { Wire } \\
\text { Model(\%) }\end{array}$ & $\begin{array}{c}\text { Line } \\
\text { Length(km) }\end{array}$ & $\begin{array}{c}\text { Voltage } \\
\text { Change(kV) }\end{array}$ \\
\hline 1 & Gulin & LGJ-150 & 11.08 & 0.940 \\
2 & Gufeng & LGJ-150 & 12.7 & 0.278 \\
3 & Guguan & LGJ-70 & 10.11 & 0.206 \\
\hline
\end{tabular}

Ratio of transformers in Chongyi all are $35 \pm 3 \times 2.5 \% / 10.5 \mathrm{kV}$, adjust capacity limit is $0.89 \mathrm{kV}$ with the first $37.45 \mathrm{kV}$, according to Table 3 , voltage change is not large, but the actual voltage is higher over High-Limit. Query to the SCADA system, the voltage change of Lintan, Liedu, Guantian, Fengzhou substation over the upper limit was caused by the $110 \mathrm{kV}$ Guting transformer fault, which transformer tap stalls in 9 levels.

In July the over High-Limit rate of Yingzigao supplied by Chongyi substation reached 33.15\%, capacity of small hydropower accessed to Yingzigao and Guobu is great, two line parallel operation, according to the calculation, the voltage change on line Congyi to Yingzigao is more than $3 \mathrm{kV}$. At the same time to ensure Congyi $10 \mathrm{kV}$ bus voltage in acceptable range, the tap adjustment in the 9 levels above.

According to the preceding analysis, the area supplied by Guting mainly due to transformer tap fault, tap controller is recommended timely to repair. Based on ETAP simulation, the control measures of Yingzigao, Guobu have been carried out. The model of Congyi distribution has been builded shown in Fig.2.

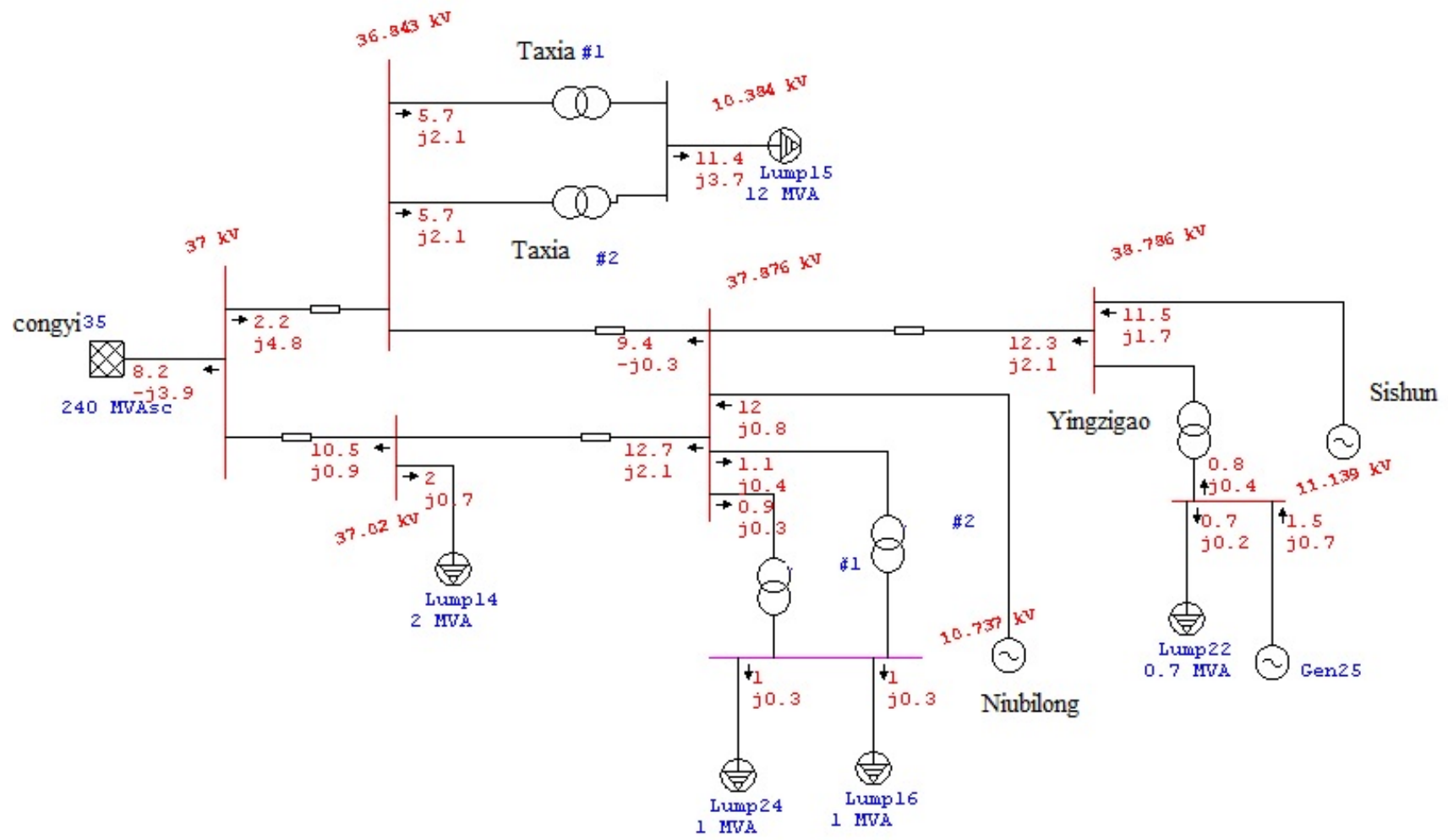

Fig. 2 simulation of Congyi distribution

Scheme 1, Guobu 35kV bus splitting operation.

If scheme 1 is adopted, based on ETAP, the simulation analysis of the distribution network is carried out, result is shown in Fig.3.the lines and the transformers are not overloaded, but Yingzigao $35 \mathrm{kV}$ bus voltage is promoted $0.5 \mathrm{kV}$, can not play the role of reducing the voltage. 


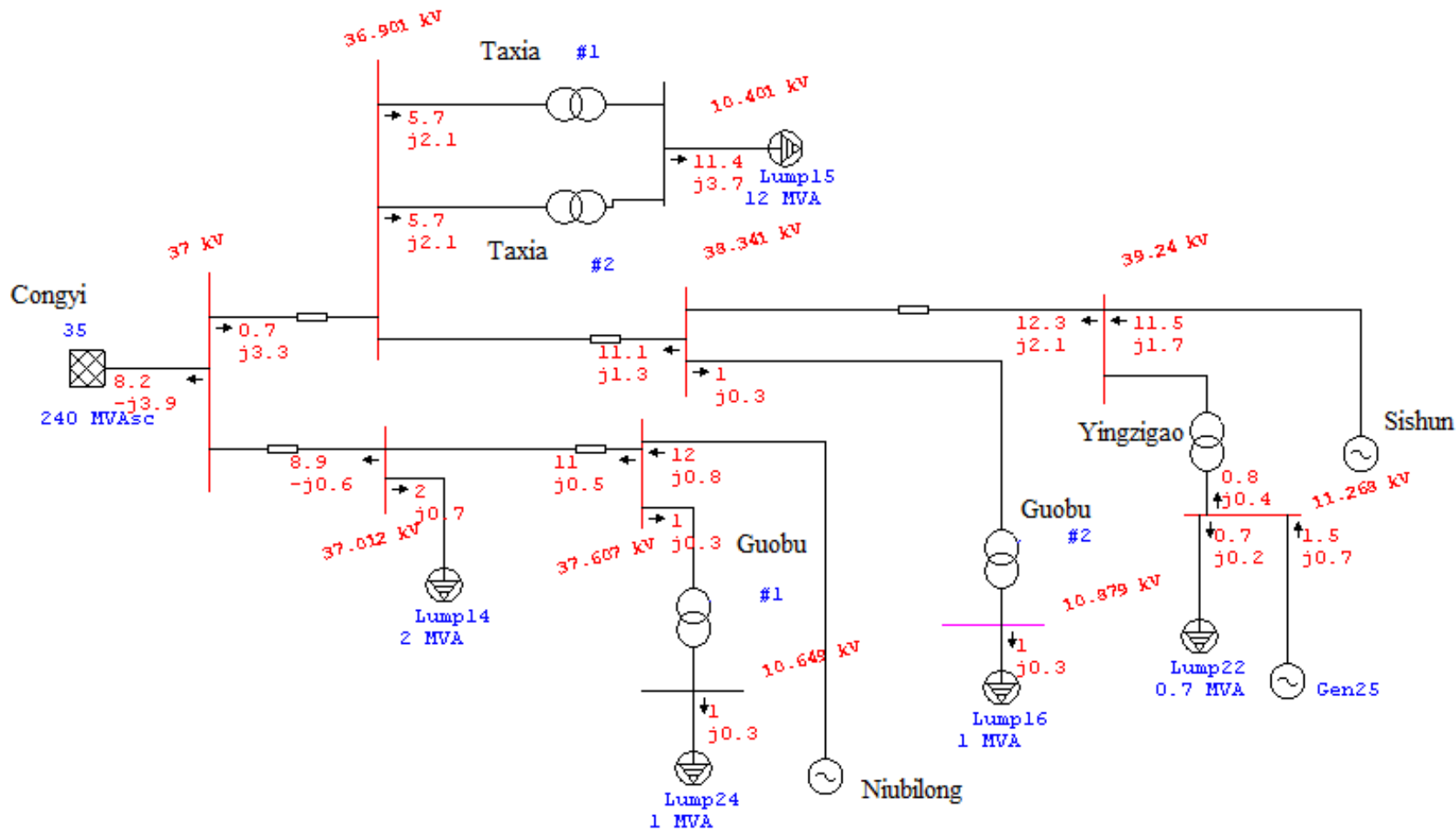

Fig.3 simulation of scheme 1

Scheme 2,replace Congyi \#1 No-load voltage regulating transformer.

$110 \mathrm{kV}$ Congyi substation has 2 transformers, \#1 No-load voltage regulating transformer is in a hot standby, \#2 On load voltage regulating transformer is operation. If the stall is adjusted back to reduce the $35 \mathrm{kV}$ bus voltage, $10 \mathrm{kV}$ bus voltage is possible to over limit, contradiction between the medium and low voltage adjustment. Replace the \#1 No-load voltage regulating transformer with on load voltage regulating transformer. \#1, \#2 transformers will be assumed $10 \mathrm{kV}, 35 \mathrm{kV}$ side load respectively, so the $35 \mathrm{kV}$ bus voltage can be fully regulated. The cost of the scheme 2 is estimated to two million yuan, the replacement cycle is long.

Scheme 3,adding reactor.

In the addition of $21 \mathrm{Mvar}$ reactor, containing interval switch. The control effect of scheme 3 is very good, the cost is estimated at 400 thousand yuan.

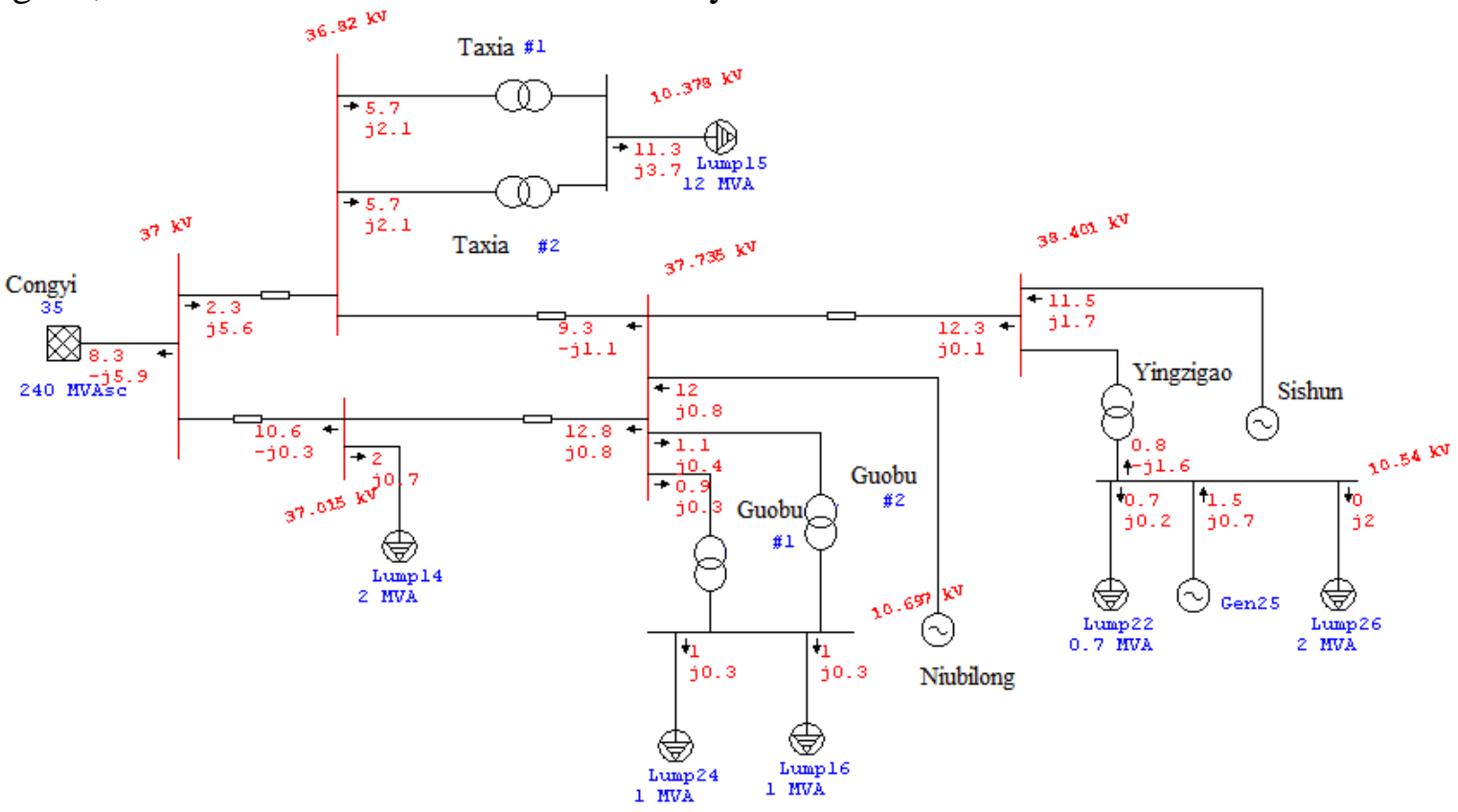

Fig.4 simulation of scheme 3 
Scheme 4, replace the wide on load voltage regulating transformer.

Replace the Yingzigao transformer with the 6.3MVA the wide on load voltage regulating transformer, which ratio is $38 \pm 4 \times 2.5 \% / 10.5$. Scheme 4 can greatly enhance the voltage regulation range, the cost is estimated to be 800 thousand yuan.

\section{Summary}

To Yingzigao over High-Limit voltage in the wet period, through the comprehensive comparison of economy, governance effect, recommendation scheme 4, replacing the wide on load voltage regulating transformer, improve $35 \mathrm{kV}$ adjustment ability greatly.

\section{Acknowledgements}

This work was financially supported by the science and technology project of State Grid(Research on voltage \& reactive power optimization control technology and auxiliary management system of rural power grid).

\section{References}

[1]Liao De, Li Zhi, "Study of the simulation of electric drive control system for SS4 electric locomotive ” Electric Drive for Locaomotives. 1999,1: 4-6

[2]Li Ronggui. “Simulating test platform for AC-DC-AC electrical locomotive[D]”, 2002.

[3]Caixia Rong, Minye Chen. Influence and Preventive Measurement of Harmonic Wave on Assembling Capacitor (in Chinese) [J]. Jiang Xi Electric Power. 2011, 2: 20-25

[4] Zhang Junjie, Xiao Xianglin, Yin Zhongdong, etc. "Simulation model of SS6B electrical locomotive based on PSCAD/EMTDC”, Electric Drive for locomotives. 2008,6:27-29

[5]Lv Yang. “Abnormal running for electrical locomotive and its simulating[D]”, 2007. 